\title{
Both Age and Disease Duration are Associated with Clinical Phenotype of Hori's Nevus in Chinese: A Retrospective Analysis of 497 Cases
}

This article was published in the following Dove Press journal: Clinical, Cosmetic and Investigational Dermatology

\author{
Yiping Zhong* \\ Lining Huang* \\ Tingting Yan \\ Yongjun Chen \\ Bin Yang (D) \\ Mao-Qiang Man (D)
}

Aesthetic Department, Dermatology Hospital, Southern Medical University, Guangzhou, Guangdong 51009I, People's Republic of China

*These authors contributed equally to this work
Correspondence: Mao-Qiang Man; Bin Yang Dermatology Hospital, Southern Medical University, Guangzhou 51009I, People's Republic of China

Tel +86-20-87257353

Email mqman@hotmail.com;

yangbinI0I@hotmail.com
Background: Hori's nevus is a common pigmented disorder on the face, preferentially in females. The clinical features have not been well characterized.

Aim: To characterize the clinical features of Hori's nevus in Chinese adults.

Subjects and Methods: Data were collected from files of patients who visited our hospital from 2015 to 2018. Age- and disease duration-related characteristics were analyzed.

Results: A total of 497 patients, including 486 females and 11 males, were included in this analysis. One fifth of the patients had a family history of Hori's nevus. Over $70 \%$ of patients were aged 21-30 years. Age at onset was comparable between males and females $(20.64 \pm$ 1.01 vs $18.99 \pm 0.24)$. Out of 497 subjects, 218 subjects $(44 \%)$ displayed yellow-brown lesions while blue-brown lesions wwere observed in 103 subjects $(21 \%)$. The rest (176 cases, $35 \%$ ) showed slate-grey lesions. Involvement in the zygomatic area was observed in 496/497 subjects. Involvement in a single area accounted for $74 \%$ of patients, while two areas were involved in $19 \%$ of patients. The number of involved areas correlated positively with disease duration. However, the proportion of subjects with yellow-brown lesions correlated negatively with disease duration, while the proportion of subjects with slate-grey lesions correlated positively with disease duration. The proportion of subjects with lesions involving the lower eyelids, the root of the nose, the temple and the outer frontal area correlated positively with age.

Conclusion: Hori's nevus mainly involves the zygomatic area in subjects aged 21-30 years. Lesion color is associated with age, age at onset, and disease duration.

Keywords: Hori's nevus, age, pigmentation

\section{Introduction}

Hori's nevus, also named acquired bilateral nevus of Ota-like macules, is a common dermal melanocytic hyperpigmentation, with a prevalence of $2.5 \%$ in the People's Republic of China. ${ }^{1}$ It is characterized by speckled brown, brown-blue, or slate-gray macules, bilaterally distributed on the zygomatic region in both males and females. ${ }^{1,2}$ However, unilateral involvement had also been reported. ${ }^{3}$ Hori's nevus can also involve other areas, such as the forehead, temporal area, eyelids, and root or alae of the nose. ${ }^{4,5}$ Since it was first reported in $1984,{ }^{4}$ there have been a number of publications pertinent to the pathogenesis, treatment and clinical characteristics of Hori's nevus. A number of factors can contribute to the development of Hori's nevus, including genetic background (a family history of Hori's nevus), ${ }^{6}$ environment (UV irradiation), ${ }^{1,6,7}$ cutaneous inflammation, ${ }^{8,9}$ as well as androgen receptor. ${ }^{10}$ It can be 
complicated with melasma, acne, and premenstrual syndrome in females. ${ }^{11}$ More males than females have lesions on the forehead. ${ }^{12}$ Although clinical features of femaledominated and favored site of zygomatic area are well known, other clinical characteristics of Hori's nevus are far less known. Therefore, here we retrospectively analyzed ageand disease duration-related characteristics of Hori's nevus in a large cohort of Chinese adullts.

\section{Subjects and Methods}

A retrospective chart review was performed on patients with Hori's nevus who visited the Dermatology Hospital of Southern Medical University, Guangzhou, the People's Republic of China from January 2015 to December 2018. Diagnosis of Hori's nevus was based on the typical features of skin lesions. Dermoscopy was used to differentiate Hori's nevus from melasma in case of uncertainty of the diagnosis. This study was approved by the institutional review board of the Dermatology Hospital of Southern Medical University (GDDHLS20190311). All data were fully anonymized, and no attempt was made to re-access clinical records for additional information. Patients' data were collected by the clinicians involved with patient care and subsequently recorded in an anonymous format. This anonymous data was then provided for future research purposes. Within our institution, patient data may be collected with a waiver of formal consent, as long as it remains fully anonymized, with no method of tracing this back to an individual patient. Therefore, formal patient consent was not required by the institutional review board. This work was carried out in compliance with the Declaration of Helsinki.

\section{Statistics}

Statistical analyses were performed, using GraphPad Prism 5.0. Data were expressed as percentages (\%). Chi- square test was used to determine the significant differences of qualitative data. Unpaired Student's $t$ test was used to determine significances between the two groups.

\section{Results}

\section{Characteristics of Patients}

A total of 497 patients, including 486 females and 11 males, with Hori's nevus were identified from patients' files. Both patients' age and age at onset were comparable between males and females (Table 1). Mean age at onset was 19.02 \pm 0.24 years (median 18; 95\% CI 18.55-19.49). Out of 497 patients, 432 (87\%) patients were Fitzpatrick skin type IV, and $13 \%$ of patients were type III. Information whether patients had a family history of Hori's nevus was not collected from 2015 to 2017. In 2018, 23 out of 109 patients (21\%) patients proclaimed a family history of Hori's nevus.

\section{Clinical Features of Hori's Nevus}

Lesions displayed brown or slate-grey or a mix of brown and slate-grey color with unclear boundaries, particularly lesions in yellow-brown color (Supplemental Figure 1). Under a dermoscope, Hori's nevus was featured by uneven distribution of pigment with involvement of hair follicles, without a typical reticular pattern (Figure 1). In contrast, melasma, a mimic of Hori's nevus in some cases, displays a reticular pattern with perifollicular sparing and even distribution of pigment. ${ }^{13-15}$ Out of the 497 patients, 218 patients $(44 \%)$ had lesions in yellow-brown color, and 176 patients $(35 \%)$ had lesions in slate-grey color. The rest, 103 patients (21\%), displayed blue-brown lesions. Lesion color, not the involved site, varied significantly with age at onset (Supplemental Table 1). All patients had bilateral involvements. A total of $74 \%$ (368) had lesions on single area, while 96 patients $(19 \%)$ had lesions on two areas. Involvement in three or more areas was found in 23 patients (5\%).

Table I Demographic Characteristics of Subjects

\begin{tabular}{|c|c|c|c|}
\hline & Females $(\mathrm{N}=486)$ & Males $(n=I I)$ & Overall ( $N=497)$ \\
\hline Age (years) (Mean \pm SEM, 95\% Cl) & $26.88 \pm 0.26 ; 95 \% \mathrm{Cl} 26.36-27.40$ & $25.09 \pm 1.05 ; 95 \% \mathrm{Cl} 22.75-27.43$ & $26.84 \pm 0.26 ; 95 \% \mathrm{Cl} 26.33-27.35$ \\
\hline Age (years) at nset (Mean \pm SEM, $95 \% \mathrm{Cl}$ ) & $18.99 \pm 0.24 ; 95 \% \mathrm{Cl} 18.51-19.47$ & $20.64 \pm 1.01 ; 95 \% \mathrm{Cl} 18.38-22.89$ & $19.02 \pm 0.24 ; 95 \% \mathrm{Cl} 18.55-19.49$ \\
\hline Disease duration (years) (Mean $\pm \mathrm{SEM}, 95 \% \mathrm{Cl}$ ) & $7.90 \pm 0.21 * ; 95 \% \mathrm{Cl} 7.491-8.303$ & $4.46 \pm 0.76 ; 95 \% \mathrm{Cl} 2.772-6.137$ & $7.82 \pm 0.20 ; 95 \% \mathrm{Cl} 7.42-8.222$ \\
\hline \multicolumn{4}{|l|}{ Fitzpatrick Skin Type (n, \%) } \\
\hline Type III & $65(13)$ & 0 & $65(13)$ \\
\hline Type IV & 421 (87) & II (100) & $432(87)$ \\
\hline
\end{tabular}

Notes: $*_{p}=0.0129$ vs males; $\mathrm{t}=2.495$. 


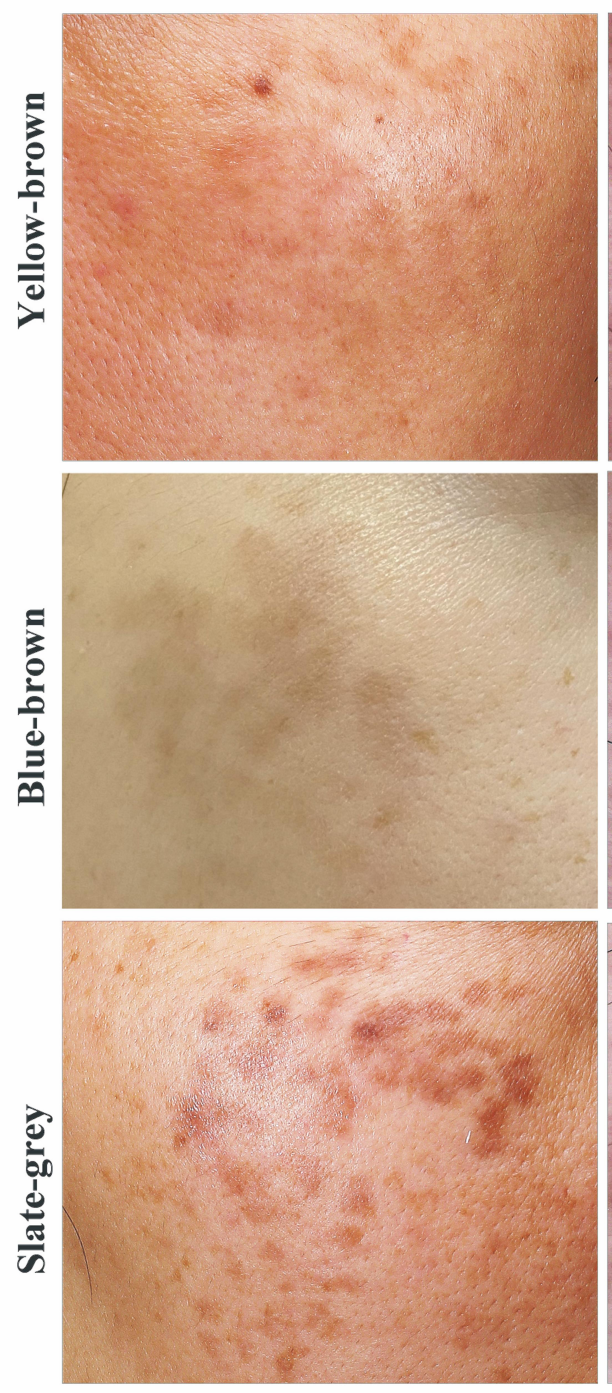

Clinical Pictures
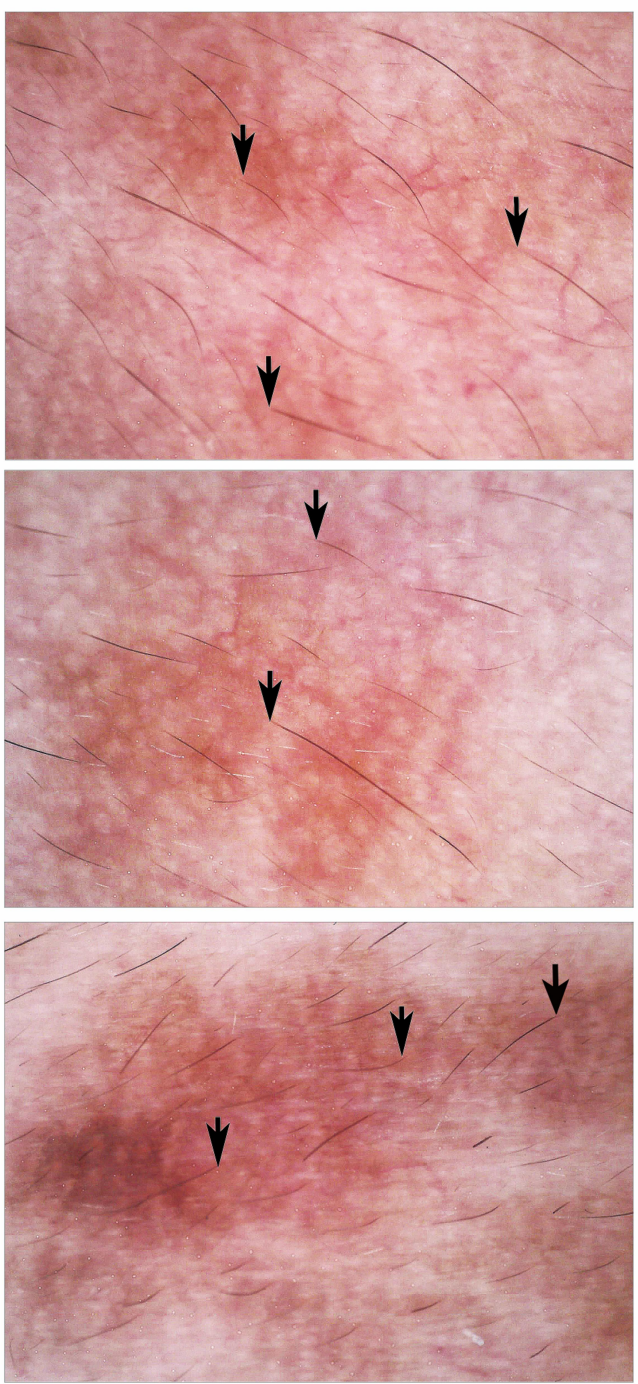

Dermoscopic Pictures

Figure I Clinical and dermoscopic images. Black arrows indicate involvement of pigment in hair follicles.

Zygomatic involvement was observed in 496 patients. Other involved areas included the forehead (11\%), the lower eyelids $(7 \%)$, the root of the nose $(5 \%)$, alae of the nose $(2 \%)$, and the temple (1\%). Although a previous study showed that more males than females had involvement on the forehead, ${ }^{12}$ we did not see such gender difference in this cohort (2/11 in males vs $51 /$ 486 in females, $p>0.05$ ).

\section{Age-Related Clinical Characteristics}

All patients, except one patient aged 27 years, had lesions on the zygomatic area. It appeared that the older the patients, the higher incidence of involvement in extra-zygomatic areas (Figure 2). The number of involved sites correlated positively with patients' age (Pearson $\mathrm{r}=0.1910, \quad 95 \%$ CI 0.1038 to 0.2753 , $p<0.0001)$. But, age at onset did not affect the number of involved sites (Supplemental Table 1). Moreover, the proportion of patients with slate-grey lesions tended to increase with age (Figure 3A. Chisquare $=3.844, p<0.05$ ). In contrast, the proportion of patients with yellow-brown lesions increased with age at onset (Figure 3B. Chi-square $=30.92, p<0.0001$ ). Lesion color varied greatly in patients aged 21-40 years old (Figure 3A. Chi-square $=39.14, p<0.0001$ for patients aged 20-21 years; Chi-square $=13.22, p<0.01$ for patients aged 31-40 years). Likewise, lesion color also differed among subjects whose age at onset was 


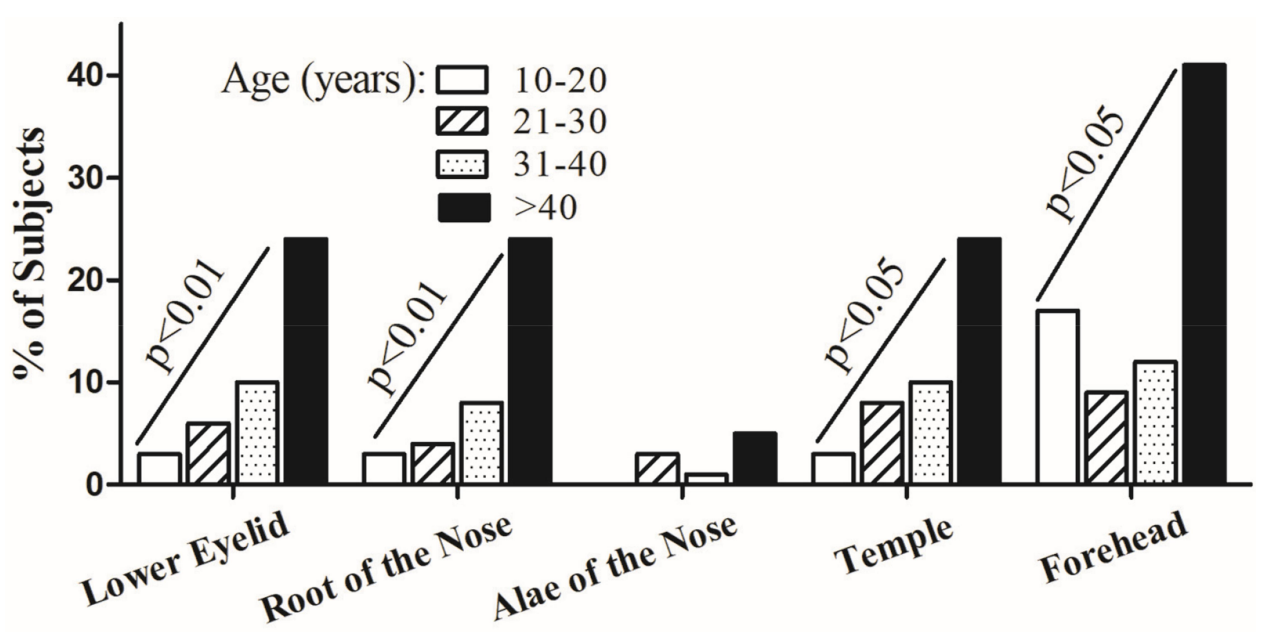

Figure 2 Age-associated characteristics of involved areas. The number of patients with extra zygomatic involvement increases with age. Chi-square test for trend was used to analyze the trend of changes. Significances are indicated in the figures.

between 11 and 40 years (Figure 3B) Thus, the lesion site, the number of involved sites, and lesion color varies with age and age at onset.

\section{Disease Duration-Related Clinical \\ Characteristics}

We next analyzed whether disease duration influences the number of involved sites. Indeed, the number of involved sites correlated positively with years of disease duration (Pearson $\mathrm{r}=0.1826$, 95\% CI 0.09614-0.2663, $p<0.0001$ ). In contrast to the effect of patients' age on involved sites (Figure 2), disease duration did not affect the involved sites (Table 2). However, lesion color was associated the disease duration. The proportion of patients with yellowbrown colored lesions decreased, while the proportion of patients with slate-grey color increased with disease duration (Figure 3C. Chi-square $=239.5, p<0.0001$ for yellowbrown color; Chi-square $=95.51, p<0.0001$ for slate-grey color). These results demonstrate that disease duration affects color of skin lesion and number of involved sites.

\section{Discussion}

Hori's nevus is a common pigmented disorder, particularly in Asian females, although males can also be involved. In the People's Republic of China, the prevalence of Hori's males and females are $0.5 \%$ and $4.2 \%$, respectively. ${ }^{1}$ Previous studies showed that median age at onset was 30 years and mean age at onset was $27.2 \pm 7.5$ years in Shanghai, the People's Republic of China,,11 while in Seoul, South Korea, the mean age at onset ranged from
31.5 to 33.1 years in males and females. ${ }^{12}$ The present study demonstrated that the median age at onset and mean age at onset were 18 and 19 years, respectively, in Guangzhou, the People's Republic of China. The differences in age at onset among these three cities (Shanghai, Seoul and Guangzhou) are likely attributable to the differences in exposure of the skin to sun, a known triggering factor for Hori's nevus. ${ }^{1,3,6,7}$ The annual cumulative UV indices in Guangzhou $\left(23.1291^{\circ} \mathrm{N}\right)$, Shanghai $\left(31.2304^{\circ} \mathrm{N}\right)$ and Seoul $\left(37.5665^{\circ} \mathrm{N}\right)$ are 120,91 and 69 , respectively. Therefore, people living in Guangzhou are generally exposed to more sunlight than those living in Shanghai and Seoul, possibly leading to an earlier onset of Hori's nevus in Guangzhou, the People's Republic of China. Thus, the present results further support a pathogenic role of sun exposure (UV irradiation) in Hori's nevus, suggesting that protecting skin from sun exposure could prevent and/or alleviate Hori's nevus. Of course, other unknown factors could also contribute to the difference in age at onset in these three cities.

Interestingly, the present study demonstrated agerelated differences in clinical characteristics, ie, the older the patients, the more likely they had involvement in other areas besides zygomatic areas. Moreover, the shorter the disease duration, the lesions tended to be lighter in color. Conversely, the longer the disease duration, the lesions tended to be darker. Changes in lesion color with disease duration could reflect a progressive pigmentation over the course of the disease. In contrast to the prior study showing involvement in the zygomatic area in $65 \%$ of patients, ${ }^{16}$ all patients had involvement in the zygomatic 

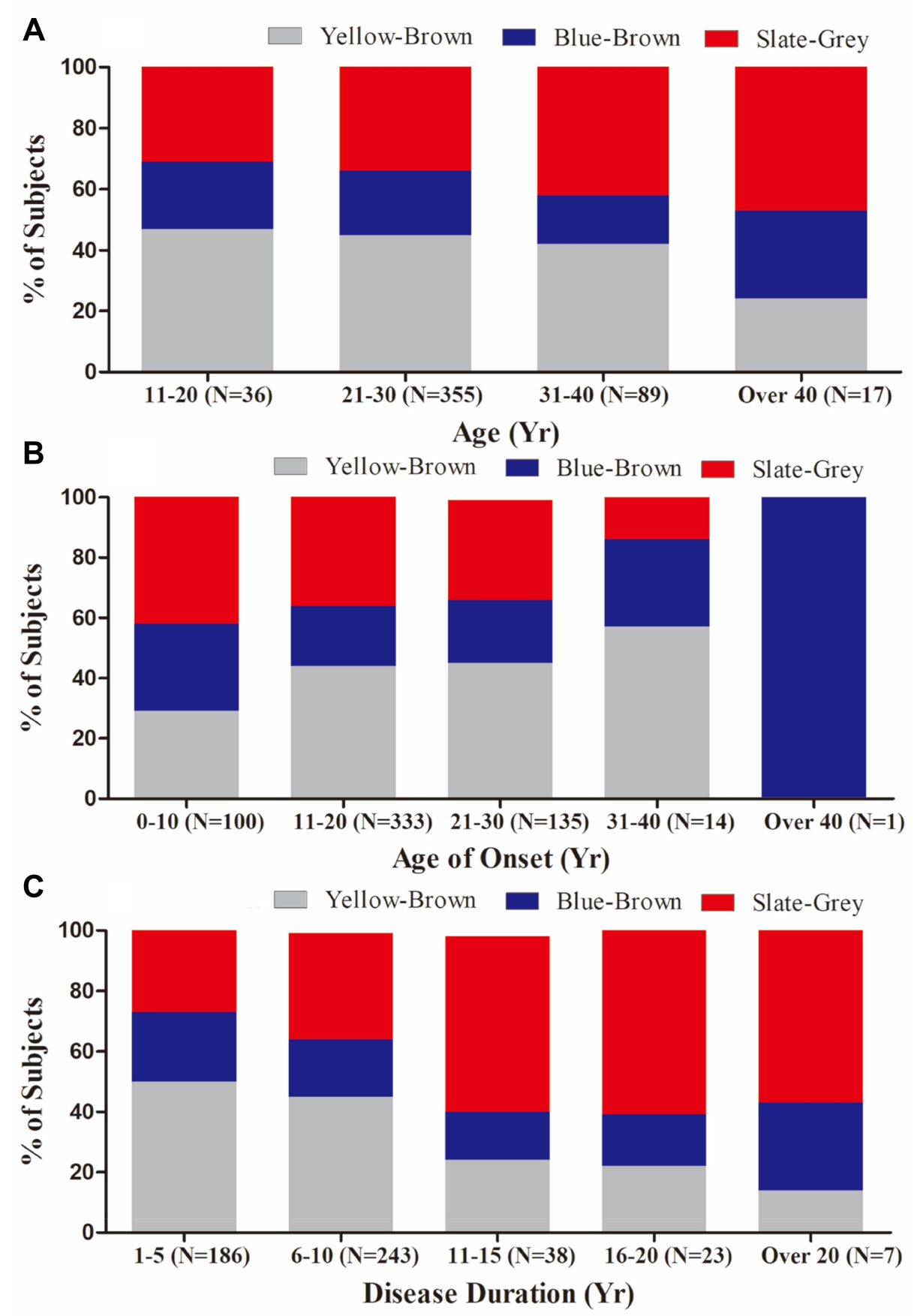

Figure 3 Age- and disease duration-associated lesion color. (A) displays lesion color among different age groups. The tendency of having slate-grey color of lesions increases with age (Chi-square=3.844, $p=0.0499$ for slate-grey color); (B) exhibits variation of lesion color with age at onset. The tendency of having yellow-brown color of lesions increases with age at onset (Chi-square $=30.92, p<0.000$ I for yellow-brown color); (C) demonstrates variation of lesion color with disease duration $($ Chi-square $=239.5$, $p<0.000$ I for yellow-brown color; Chi-square $=95.51, p<0.0001$ for slate grey color). Chi-square test for trend was used to determine the significance.

area in the present study. The reasons for these discrepant findings remain unknown. Nevertheless, the present study clearly demonstrated that both age and disease duration are associated with lesion color and involved skin sites of Hori's nevus.
In conclusion, both older subjects and subjects with longer disease duration tend to have slate-grey lesions, while subjects with shorter disease duration tend to have yellow-brown lesions. Additionally, the longer the disease duration, the more areas are involved. Protection of skin 
Table 2 Disease Duration-Related Clinical Characteristics

\begin{tabular}{|c|c|c|c|c|c|c|c|}
\hline \multirow{2}{*}{$\begin{array}{l}\text { Duration } \\
\text { (years) }\end{array}$} & \multirow[t]{2}{*}{ Gender (N) } & \multicolumn{6}{|c|}{ Involved Sites [N (\%)] } \\
\hline & & $\begin{array}{l}\text { Zygomatic } \\
\text { Area }\end{array}$ & $\begin{array}{l}\text { Lower } \\
\text { Eyelid }\end{array}$ & Root of the Nose & Alae of the Nose & Temple & Forehead \\
\hline $\mathrm{I}-5$ & $\begin{array}{l}\text { Females (I78) } \\
\text { Males (8) }\end{array}$ & $\begin{array}{l}178(100) \\
8(100)\end{array}$ & $\begin{array}{l}12(7)^{d} \\
0^{c}\end{array}$ & $\begin{array}{l}7(4)^{d} \\
0^{c}\end{array}$ & $\begin{array}{l}I(1)^{d} \\
I(13)^{b}\end{array}$ & $\begin{array}{l}9(5)^{d} \\
0^{c}\end{array}$ & $\begin{array}{l}20(I I)^{d} \\
3(38)^{a}\end{array}$ \\
\hline $6-10$ & $\begin{array}{l}\text { Females (240) } \\
\text { Males (3) }\end{array}$ & $\begin{array}{l}239(100) \\
3(100)\end{array}$ & $\begin{array}{l}13(5)^{d} \\
0\end{array}$ & $\begin{array}{l}14(6)^{d} \\
0\end{array}$ & $\begin{array}{l}8(3)^{d} \\
0\end{array}$ & $\begin{array}{l}20(8)^{d} \\
0\end{array}$ & $\begin{array}{l}22(9)^{d} \\
I(33)\end{array}$ \\
\hline $11-15$ & $\begin{array}{l}\text { Females (38) } \\
\text { Males (0) }\end{array}$ & $\begin{array}{l}38(100) \\
0\end{array}$ & $\begin{array}{l}5(13)^{d} \\
0\end{array}$ & $\begin{array}{l}2(5)^{d} \\
0\end{array}$ & $\begin{array}{l}0^{d} \\
0\end{array}$ & $\begin{array}{l}7(18)^{d} \\
0\end{array}$ & $\begin{array}{l}4(11)^{d} \\
0\end{array}$ \\
\hline $16-20$ & $\begin{array}{l}\text { Females (23) } \\
\text { Males (0) }\end{array}$ & $\begin{array}{l}23(100) \\
0\end{array}$ & $\begin{array}{l}3(13)^{d} \\
0\end{array}$ & $\begin{array}{l}2(9)^{d} \\
0\end{array}$ & $\begin{array}{l}2(9)^{d} \\
0\end{array}$ & $\begin{array}{l}7(30)^{d} \\
0\end{array}$ & $\begin{array}{l}5(22)^{d} \\
0\end{array}$ \\
\hline$>20$ & $\begin{array}{l}\text { Females }(7) \\
\text { Males }(0)\end{array}$ & $\begin{array}{l}7(100) \\
0\end{array}$ & $\begin{array}{l}2(29)^{\mathrm{a}} \\
0\end{array}$ & $\begin{array}{l}2(29)^{\mathrm{a}} \\
0\end{array}$ & $\begin{array}{l}0^{c} \\
0\end{array}$ & $\begin{array}{l}\text { I }(14)^{\mathrm{b}} \\
0\end{array}$ & $\begin{array}{l}2(29)^{a} \\
0\end{array}$ \\
\hline
\end{tabular}

Notes: Fisher's exact test was used to analyze significance in prevalence. ${ }^{a} p<0.05,{ }^{b} p<0.0$ I, ${ }^{c} p<0.00$ I, and ${ }^{d} p<0.000$ I between the zygomatic area and other areas. No significant differences were found between males and females.

from sun exposure could possibly prevent and/or alleviate Hori's nevus.

\section{Funding}

There is no funding to report.

\section{Disclosure}

The authors report no conflicts of interest in this work.

\section{References}

1. Wang BQ, Shen ZY, Fei Y, et al. A population-based study of acquired bilateral nevus-of-Ota-like macules in Shanghai, China. $J$ Invest Dermatol. 2011;131(2):358-362.

2. Sun CC, Lu YC, Lee EF, et al. Naevus fusco-caeruleus zygomaticus. Br J Dermatol. 1987;117(5):545-553.

3. Ee HL, Wong HC, Goh CL, Ang P. Characteristics of Hori naevus: a prospective analysis. Br J Dermatol. 2006;154(1):50-53.

4. Hori Y, Kawashima M, Oohara K, et al. Acquired bilateral nevus of Ota-like macules. J Am Acad Dermatol. 1984;10(6):961-964.

5. Hidano A. Acquired bilateral nevus of Ota-like macules. $J$ Am Acad Dermatol. 1985;12(2 Pt 1):368-369.

6. Mizoguchi M, Murakami F, Ito M, et al. Clinical, pathological, and etiologic aspects of acquired dermal melanocytosis. Pigment Cell Res. 1997;10(3):176-183.

7. Murakami F, Baba T, Mizoguchi M. Ultraviolet-induced generalized acquired dermal melanocytosis with numerous melanophages. $\mathrm{Br}$ J Dermatol. 2000;142(1):184-186.
8. Murakami F, Soma Y, Mizoguchi M. Acquired symmetrical dermal melanocytosis (naevus of Hori) developing after aggravated atopic dermatitis. Br J Dermatol. 2005;152(5):903-908.

9. Lee JY, Kim EH, Kim KH, et al. Acquired bilateral naevus of Ota-like macules: an immunohistological analysis of dermal melanogenic paracrine cytokine networks. Br J Dermatol. 2011;164 (3):580-585.

10. Long TF, Liu L, He L, et al. Androgen, estrogen and progesterone receptors in acquired bilateral nevus of Ota-like macules. Pigment Cell Melanoma Res. 2010;23(1):144-146.

11. Zhang Q, Jiang P, Tan C, Yang G. Clinical profile and triggering factors for acquired, bilateral nevus of Ota-like macules. Cutan Ocul Toxicol. 2017;36(4):327-330.

12. Lee WJ, Lee GY, Won KH, et al. Comparison of acquired bilateral nevus of Ota-like macules in men and women. Indian J Dermatol Venereol Leprol. 2014;80(4):313-319.

13. Yalamanchili R, Shastry V, Betkerur J. Clinico-epidemiological study and quality of life assessment in melasma. Indian $J$ Dermatol. 2015;60(5):519.

14. Sonthalia S, Jha AK, Langar S. Dermoscopy of melasma. Indian Dermatol Online J. 2017;8:525-526.

15. Revathi TN. A study of dermoscopic features in facial melanosis and its clinical co-relation- an observational study. Int $J$ Dermatol Cosmet. 2017;1(1):11-20.

16. Wang B, Xie HF, Tan J, et al. Induction of melasma by 1064-nm Q-switched neodymium: yttrium-aluminum-garnet laser therapy for acquired bilateral nevus of Ota-like macules (Hori nevus): a study on related factors in the Chinese population. $J$ Dermatol. 2016;43 (6):655-661. 


\section{Publish your work in this journal}

Clinical, Cosmetic and Investigational Dermatology is an international, peer-reviewed, open access, online journal that focuses on the latest clinical and experimental research in all aspects of skin disease and cosmetic interventions. This journal is indexed on CAS.
The manuscript management system is completely online and includes a very quick and fair peer-review system, which is all easy to use. Visit http://www.dovepress.com/testimonials.php to read real quotes from published authors.

Submit your manuscript here: https://www.dovepress.com/clinical-cosmetic-and-investigational-dermatology-journal 